\title{
Gas Phase H/D Exchange of Sodiated Amino Acids: Why Do We See Zwitterions?
}

\author{
Marko Rožman, ${ }^{*}$ Branimir Bertoša, ${ }^{+}$Leo Klasinc, ${ }^{*}$ \\ and Dunja Srzic* \\ Ruđer Boškovic Institute, Zagreb, Croatia
}

\begin{abstract}
The gas-phase interaction of sodiated amino acids and sodiated amino acid methyl esters with various deuterium donors is investigated by combining results of $H / D$ exchange reactions with those from density functional theory and molecular dynamics calculations. Discrepancy between experimentally and theoretically obtained structures for sodium cationized amino acids is explained by deuterium donor caused perturbation of the most stable amino acid conformation. Detailed study of H/D exchange mechanism on sodiated amino acids shows that the H/D exchange reaction is preceded by a multistep quasi-isoenergetic transition (perturbation) from a charge solvated to zwitterionic structure in the amino acid. Although the computation refers to the system $\mathrm{AlaNa}^{+}$and $\mathrm{D}_{2} \mathrm{O}$, these mechanisms apply to all amino acids, except those where a functional side-chain group takes part in the perturbation process. The suggested perturbation mechanism applies also for other deuterium donors such as $\mathrm{CD}_{3} \mathrm{OD}$ or even $\mathrm{ND}_{3}$ and indicates that a single water molecule suffices to convert the sodiated amino acid from charge solvated to zwitterionic form. (J Am Soc Mass Spectrom 2006, 17, 29-36) (C) 2005 American Society for Mass Spectrometry
\end{abstract}

G as-phase $\mathrm{H} / \mathrm{D}$ exchange is one of the techniques for structural investigation of biomolecules [1-9]. Site-specific treatment of H/D exchange reaction on protonated amino acids provided evidence for their structure, which was found also to be in agreement with the calculated structure [1-9]. Complexation of amino acids with alkali metal ions stabilizes the amino acid gas-phase zwitterionic structure (ZW). Site-specific treatment of the $H / D$ exchange reaction on sodiated amino acids is ideal for distinction between charge solvated (CS) and zwitterionic (i.e., salt bridged) structures. However, for sodiated amino acids, structural information may differ from that obtained by calculation [10, 11]. Because in the H/D exchange reaction sodiated amino acid interacts with a neutral molecule of deuterating agent, it is suggested that this interaction may perturb the conformation of sodiated amino acid and, thus, influence the experimental results and, thereby, the conclusions.

In a recent study, Cox et al. [10] proposed mechanisms for H/D exchange of sodiated glycine oligomers with $\mathrm{ND}_{3}$. The exchange mechanism was studied by density functional theory (DFT) at the B3LYP/6-311 $++\mathrm{G}^{* *}$ level in a way that reaction intermediates were determined and then connected with the proposed reaction coordinate. According to

Published online December 15, 2005

Address reprint requests to Dr. D. Srzic, Laboratory for Chemical Kinetics and Atmospheric Chemistry, Ruđer Boškovic Institute, Bijenička 54, HR10002 Zagreb, Croatia. E-mail: andrew.emili@utoronto.ca

* Laboratory for Chemical Kinetics and Atmospheric Chemistry.

† Laboratory of Chemical and Biological Crystallography. their proposed mechanism, perturbation of sodium cationized glycine from the CS to the $\mathrm{ZW}$ form is a result of $\mathrm{H} / \mathrm{D}$ exchange of carboxylic hydrogen. The transition states and exact reaction energy profiles were not investigated. Also, it was not shown that the reaction follows the proposed reaction coordinate. If $\mathrm{H} / \mathrm{D}$ exchange follows this mechanism through the first $H / D$ exchange, the next one will take place in the $\mathrm{ZW}$ form of glycine. Exchange in the $\mathrm{ZW}$ form implies a different mechanism, which will probably yield different reaction rate constants for the remaining two hydrogens. Thus, the proposed mechanism predicts two reaction sites as identical and one to be different, which is clearly at odds with experimental data.

The purpose of this work is to answer the question in the title. It will be shown that experiment "designed" for structural investigation may change the structure of the analite. For that purpose, experimental (mass spectrometry) and theoretical (DFT and molecular dynamics) results were employed. Detailed description of the dynamic pathway for the $\mathrm{H} / \mathrm{D}$ exchange reaction of sodiated alanine $\left(\mathrm{AlaNa}^{+}\right)$with $\mathrm{D}_{2} \mathrm{O}$ is given. $\mathrm{AlaNa}^{+}$is used as model compound for all amino acids, except for those in which a functional side-chain group takes part in the perturbation process. The proposed perturbation mechanism which converts a sodiated amino acid from CS to ZW form applies also for other deuterium donors such as $\mathrm{CD}_{3} \mathrm{OD}$ and even $\mathrm{ND}_{3}$. Furthermore, this mechanism shows that a single molecule of water is adequate for the conversion. 
Table 1. Site specific H/D exchange reaction rate constants (in units of $10^{-11} \mathrm{~cm}^{3} \mathrm{~s}^{-1}$ molecules ${ }^{-1}$ ) for studied amino acids

\begin{tabular}{|c|c|c|c|c|c|c|c|c|}
\hline \multirow{2}{*}{$\begin{array}{l}\text { Amino acid } \\
\text { Deuterium donor }\end{array}$} & \multicolumn{2}{|c|}{$\mathrm{AlaNa}^{+}$} & \multicolumn{2}{|c|}{$\mathrm{AspNa}^{+}$} & \multicolumn{2}{|c|}{ CysNa ${ }^{+}$} & \multicolumn{2}{|c|}{$\mathrm{GluNa}^{+}$} \\
\hline & $\mathrm{CH}_{3} \mathrm{OD}$ & $\mathrm{D}_{2} \mathrm{O}$ & $\mathrm{CH}_{3} \mathrm{OD}$ & $\mathrm{D}_{2} \mathrm{O}$ & $\mathrm{CH}_{3} \mathrm{OD}$ & $\mathrm{D}_{2} \mathrm{O}$ & $\mathrm{CH}_{3} \mathrm{OD}$ & $\mathrm{D}_{2} \mathrm{O}$ \\
\hline$k_{1}$ & 20.5 & 1.5 & 4.6 & 3.6 & 1.6 & 0.4 & 3.5 & 3.1 \\
\hline$k_{2}$ & \multirow{3}{*}{$\begin{array}{l}20.5 \\
20.5\end{array}$} & 1.5 & 1.1 & 0.5 & 1.6 & 0.4 & 1.6 & 0.9 \\
\hline$k_{3}$ & & 1.5 & 1.1 & 0.5 & \multirow[t]{2}{*}{1.6} & 0.4 & 1.6 & 0.9 \\
\hline$k_{4}$ & & & 1.1 & 0.5 & & & 1.6 & 0.9 \\
\hline Amino acid & \multicolumn{3}{|c|}{$\mathrm{IleNa}^{+}$} & \multicolumn{2}{|c|}{ LeuNa $^{+}$} & & \multicolumn{2}{|c|}{ ValNa ${ }^{+}$} \\
\hline Deuterium donor & $\mathrm{CH}$ & & $\mathrm{D}_{2} \mathrm{O}$ & $\mathrm{CH}_{3} \mathrm{OD}$ & $\mathrm{D}_{2} \mathrm{O}$ & & $\mathrm{CH}_{3} \mathrm{OD}$ & $\mathrm{D}_{2} \mathrm{O}$ \\
\hline$k_{1}$ & & & 1.3 & 13.1 & 1.6 & & 9.8 & 0.2 \\
\hline$k_{2}$ & & & 1.3 & 13.1 & 1.6 & & 9.8 & 0.2 \\
\hline$k_{3}$ & & & 1.3 & 13.1 & 1.6 & & 9.8 & 0.2 \\
\hline
\end{tabular}

\section{Methods}

\section{Experimental Methods}

All amino acids (Ala, Asp, Cys, Glu, Ile, Leu, Val) and amino acid methyl esters (AlaOMe, LeuOMe, ValOMe) were obtained from Fluka (Buchs, Switzerland). The deuteration reagent $\mathrm{D}_{2} \mathrm{O}(99.8 \%)$ was from Aldrich (Milwaukee, WI) and $\mathrm{CD}_{3} \mathrm{OD}(99.8 \%)$ was from Cambridge Isotope Laboratories (Andover, MA). MALDI samples were prepared with a standard dried-droplet procedure using 2,5-dihydroxybenzoic acid (DHB) as matrix. Two consecutive $337 \mathrm{~nm}$ laser pulses from a nitrogen laser (VSL 337 NSD, LSI Laser Science, Newton, MA) were used to produce gas-phase samples. The $\mathrm{H} / \mathrm{D}$ exchange experiments were performed in a $3 \mathrm{~T}$ Fourier transform ion cyclotron resonance (FTICR) mass spectrometer (Extrel FTMS 2001, Madison, WI). Stabilized reagent gas pressure used in the exchange experiments was $2.67-1.33 \cdot 10^{-5} \mathrm{~Pa}$ at ambient temperature of $300 \mathrm{~K}$. The H/D exchange experiments and determination of the site-specific reaction rate constants were performed by using the earlier described procedure [7]. Repetitive H/D exchange experiments indicate a relative standard deviation of up to $30 \%$ for the reported site-specific rate constants.

\section{Computational Methods}

Density functional theory (DFT) and G3(MP2) [12] theory calculations were carried out by using GAUSSIAN 03 [13] program package on the computer cluster at the Ruder Boskovic Institute. Initial search of minima on potential energy surface (PES) were performed by using B3LYP functional with $6-31 \mathrm{G}^{*}$ basis set. Obtained geometries were additionally reoptimized at the B3LYP /6-311 $++G^{* *}$ level. Each stationary point (minimum on the potential energy surface) was tested by a vibrational analysis. The structures of the transition states were obtained by QST2 and QST3 optimization. Transition states structures were tested by verifying that one of the harmonic frequencies is imaginary, and by IRC analysis for the reaction pathways. Obtained energies of reactants and reaction intermediates were not corrected for zero point energy. Basis set superposition error (BSSE) was not calculated because it was assumed that relative energies of studied sodiated structures are independent of BSSE.

Since DFT gives only stationary structures, descriptions of reaction system sodiated amino acid-deuterium donor were supplemented with molecular dynamics (MD) simulations [4]. Molecular dynamics simulations were performed using MacroModel software [14] with AMBER* all atom force field. Several different MD simulations were performed depending which effect was studied. Most of the simulations were performed at $300 \mathrm{~K}$ with no SHAKE algorithm. MD simulations were carried out for 200 ps with time step of $1.5 \mathrm{fs}$.

\section{Results and Discussion}

\section{H/D Exchange Reactions}

To test the mechanism and increase the number of investigated sodiated amino acids in H/D exchange the gas-phase reactions of $\mathrm{AlaNa}^{+}, \mathrm{AspNa}^{+}, \mathrm{CysNa}^{+}$, $\mathrm{GluNa}^{+}, \mathrm{IleNa}^{+}, \mathrm{LeuNa}^{+}$, and $\mathrm{ValNa}^{+}$with $\mathrm{CD}_{3} \mathrm{OD}$ and $\mathrm{D}_{2} \mathrm{O}$ were analyzed and site-specific exchange reaction rate constants were determined, Table 1 . No exchange of hydrogens was observed in $\mathrm{AlaOMeNa}{ }^{+}$, $\mathrm{LeuOMeNa}^{+}$, and $\mathrm{ValOMeNa}{ }^{+}$.

Experimental results indicate all studied sodiated amino acids to be present in their ZW forms, at odds with available theoretically determined structures [1520]. Present findings, together with earlier results [10, 11 indicate that in $H / D$ exchange experiments only the ZW form of sodiated amino acid is probed. To answer the question why is that so, gas-phase interaction of sodiated amino acid with a deuterium donor was analyzed theoretically. For practical reasons (computational time and resources), the computational study aimed to explain the mechanism of $\mathrm{H} / \mathrm{D}$ exchange was carried out for the model system $\mathrm{AlaNa}^{+}$and $\mathrm{D}_{2} \mathrm{O}$. In all calculations, the molecule of $\mathrm{D}_{2} \mathrm{O}$ was mimicked with $\mathrm{H}_{2} \mathrm{O}$. However, because $\mathrm{CD}_{3} \mathrm{OD}$ and $\mathrm{D}_{2} \mathrm{O}$ exhibit 


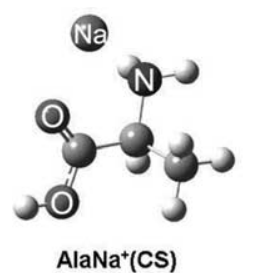

Figure 1. The most stable conformers of $\mathrm{AlaNa}^{+}$in a CS and $\mathrm{ZW}$ form at the B3LYP $/ 6-311++G^{* *}$.

similar reactivities in experiments, and because both participate only with a single deuterium exchange per reactive encounter, the mechanism also applies for $\mathrm{CD}_{3} \mathrm{OD}$.

\section{Interaction of $\mathrm{AlaNa}^{+}$and $\mathrm{D}_{2} \mathrm{O}$}

$\mathrm{H} / \mathrm{D}$ exchange reaction begins with molecules $\mathrm{D}_{2} \mathrm{O}$ and $\mathrm{AlaNa}^{+}$approaching each other. It is expected that $\mathrm{AlaNa}^{+}$is in its energetically most favorable conformation $[7,21]$. Theoretical B3LYP $/ 6-311++\mathrm{G}^{* *}$ calculations $[16,19,20]$ have shown as the most stable conformation of $\mathrm{AlaNa}^{+}$a structure, $\mathrm{AlaNa}^{+}(\mathrm{CS})$, depicted in Figure 1, in accordance with our calculations. This most stable conformation of $\mathrm{AlaNa}^{+}$is in a charge solvated form while the most stable zwitterionic form, $\mathrm{AlaNa}^{+}(\mathrm{ZW})$, is less stable by $5.2 \mathrm{~kJ} \mathrm{~mol}^{-1}$, Figure 1 .

According to the Boltzmann distribution at $300 \mathrm{~K}$, approximately $10 \%$ of $\mathrm{AlaNa}^{+}$population should be in ZW form, which raises the question whether the experiment probes only this part of total $\mathrm{AlaNa}^{+}$population. Adding the zero point energy correction yields additional stabilization of CS form by $0.4 \mathrm{~kJ} \mathrm{~mol}^{-1}$ while anharmonic effect at the B3LYP/6-311++ $\mathrm{G}^{* *}$ reduces the difference between CS and $\mathrm{ZW}$ form by $0.4 \mathrm{~kJ}$ $\mathrm{mol}^{-1}$. For more accurate results, G3(MP2) computational protocol was applied. The energy difference between CS and ZW form obtained with G3(MP2) calculations is $12 \mathrm{~kJ} \mathrm{~mol}^{-1}$, which strongly favors CS structure. Confirmation that all $\mathrm{AlaNa}^{+}$ions undergo $\mathrm{H} / \mathrm{D}$ exchange can be found in the experimental results, e.g., time plot of the experimental intensities, Figure 2. The experimental decay of the reactant in an experiment which probes only $10 \%$ of the ion population with the rest unreactive certainly will look different from that in Figure 2. On the basis of these facts, it can be concluded that almost all $\mathrm{AlaNa}^{+}$ions are in CS form and all $\mathrm{AlaNa}^{+}$population undergoes $\mathrm{H} / \mathrm{D}$ exchange. Further support that CS form of $\mathrm{AlaNa}^{+}$is initially formed comes also from vibrational spectra of $\mathrm{GlyNa}^{+}$ [22], which favored CS form of GlyNa ${ }^{+}$.

Molecular dynamics simulations of collisions of $\mathrm{AlaNa}^{+}(\mathrm{CS})$ with $\mathrm{D}_{2} \mathrm{O}$ from various directions have shown that 3 to 7 ps is needed for $\mathrm{D}_{2} \mathrm{O}$ to reach the cation, Figure 3a. The structure depicted in Figure 3a is also the most stable conformation of $\mathrm{AlaNa}^{+}-\mathrm{D}_{2} \mathrm{O}$ reaction complex. When $\mathrm{D}_{2} \mathrm{O}$ approaches the carboxylic

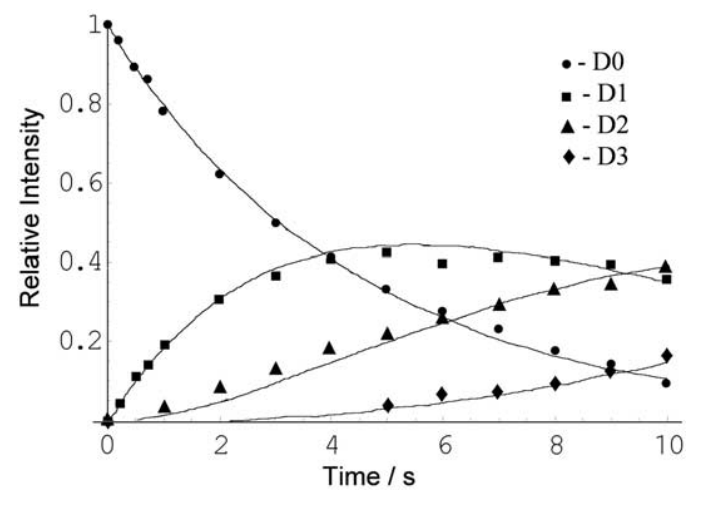

Figure 2. Time plot of the experimental intensities and the corresponding theoretical fit obtained with site-specific treatment of the H/D exchange of $\mathrm{AlaNa}^{+}$with $\mathrm{D}_{2} \mathrm{O}$. D0, D1, D2, and D3 represent the relative intensities of $\mathrm{AlaNa}^{+}$in which $0,1,2$, and 3 hydrogen atoms have been replaced by deuterium.

group it spends there $5 \mathrm{ps}$ and then shifts towards the sodium cation, Figure $3 b$ (vide infra).

Figure 3a shows that there is no possibility for $\mathrm{H} / \mathrm{D}$ exchange in the most stable reaction complex conformation, $\mathrm{AlaNa}^{+}(\mathrm{CS})-\mathrm{D}_{2} \mathrm{O}$, because $\mathrm{D}_{2} \mathrm{O}$ is fixed in the proximity of sodium cation. Sodium cation complexation also excludes amino group and carboxyl oxygen as possible sites for stabilization of $\mathrm{D}_{2} \mathrm{O}$ and $\mathrm{H} / \mathrm{D}$ exchange. However, experimental results for $\mathrm{AlaNa}^{+}$ point to three equally fast exchanging sites attributable to protonated $\alpha$-amino group, and consequently to the existence of $\mathrm{AlaNa}^{+}$in the $\mathrm{ZW}$ form. One concludes that before $\mathrm{H} / \mathrm{D}$ exchange, the structure of $\mathrm{AlaNa}^{+}$is perturbed from the CS to the ZW form, with deuterium donor acting as a catalyst. After perturbation, a new reaction complex $\mathrm{AlaNa}^{+}(\mathrm{ZW})-\mathrm{D}_{2} \mathrm{O}$ is formed and it undergoes the $\mathrm{H} / \mathrm{D}$ exchange.

\section{The Perturbation Reaction}

B3LYP /6-311 $++\mathrm{G}^{* *}$ potential energy profile together with optimized structures for the $\mathrm{D}_{2} \mathrm{O}$ catalyzed pertur-

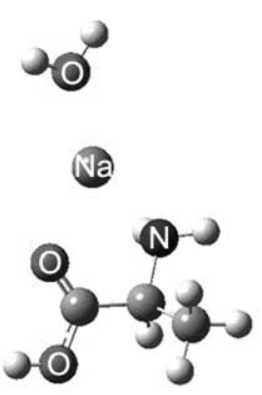

a)

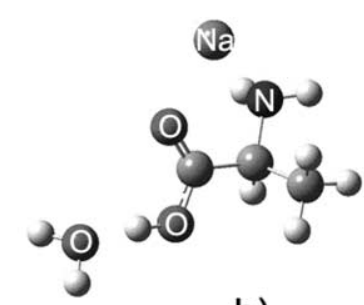

b)
Figure 3. (a) The most stable conformation of the reaction complex AlaNa ${ }^{+}(\mathrm{CS})-\mathrm{D}_{2} \mathrm{O}$. (b) Reaction complex CSK1 obtained by B3LYP/6-311+ + $\mathrm{G}^{* *}$ optimization of the situation which arises from approach of $\mathrm{D}_{2} \mathrm{O}$ towards the carboxylic group. 


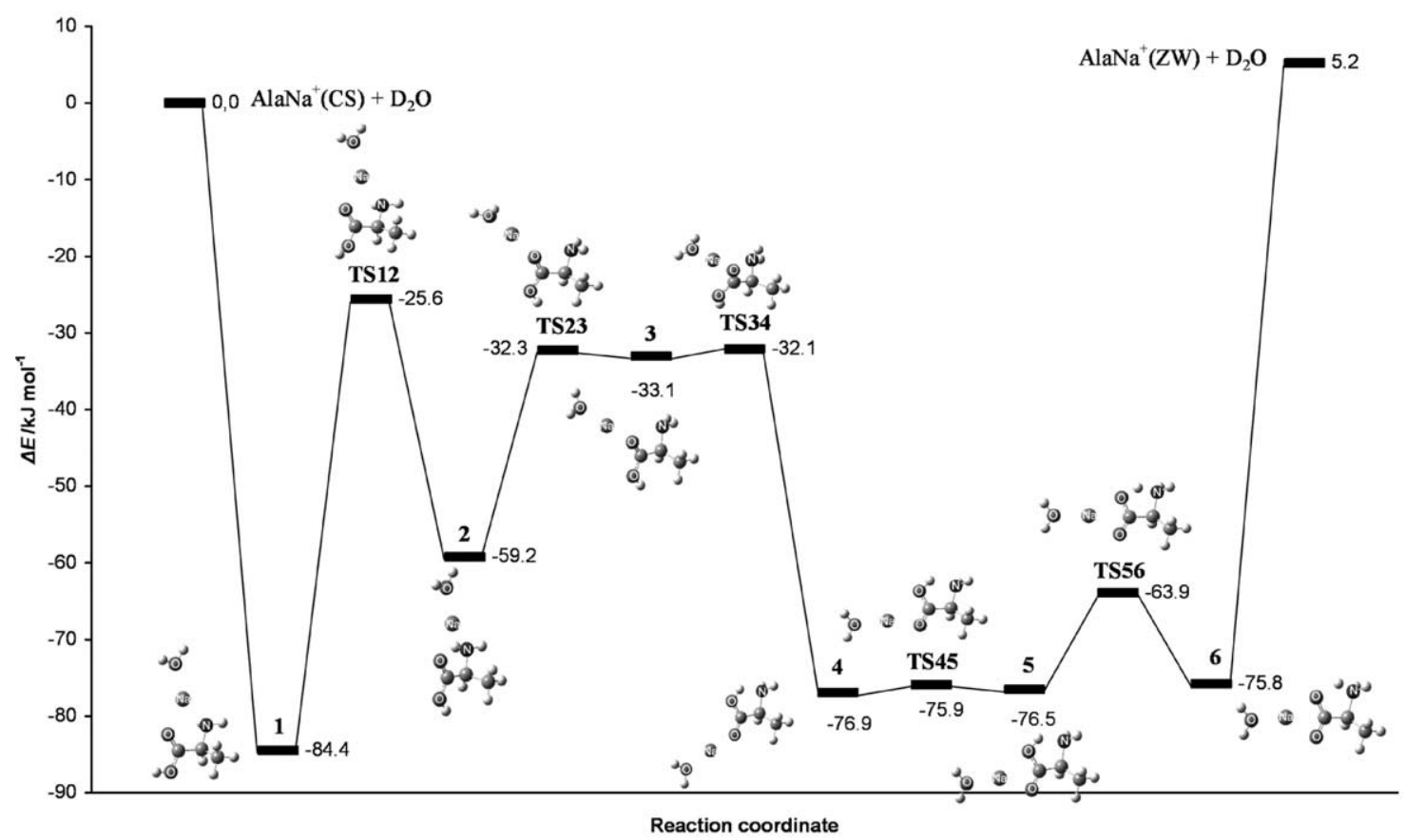

Figure 4. Schematic representation of the potential energy profile for the $\mathrm{D}_{2} \mathrm{O}$ catalyzed perturbation of $\mathrm{AlaNa}^{+}$structure from $\mathrm{CS}$ to $\mathrm{ZW}$ form. The relative energies are calculated at the B3LYP / 6-311 + $+\mathrm{G}^{* *}$ level of theory.

bation of $\mathrm{AlaNa}^{+}$structure from CS to $\mathrm{ZW}$ form is shown in Figure 4.

The reaction begins with a rotation of carboxylic group's hydrogen by $180^{\circ}$ leading to minimum 2 via transition-state TS12. It is followed by a shift of triply coordinated sodium in $\mathbf{2}$ to a doubly coordinated in intermediate 3. The $\mathrm{D}_{2} \mathrm{O}$ molecule accompanies and coordinates the sodium cation during the transition. Unfortunately, attempts to identify corresponding transition-state failed, probably because of the very low potential energy barrier between transition-state TS23 and reaction intermediate 3 of only $0.8 \mathrm{~kJ} \mathrm{~mol}^{-1}$. Structural similarity between TS23 and intermediate 3 is a consequence of a very shallow potential energy surface. Transition-state TS23 (Figure 4) is found by QST3 optimization. Additional vibration analysis characterized this structure as a second-order saddle point with two imaginary frequencies. Animated vibration of one $\left(16.03 \mathrm{i} \mathrm{cm}^{-1}\right)$ corresponds to displacement of $\mathrm{Na}^{+}$and $\mathrm{D}_{2} \mathrm{O}$ along the reaction coordinate, and it tends to lead in the direction of reaction intermediates 2 and 3 . Animation of the other imaginary frequency (38.78i $\mathrm{cm}^{-1}$ ) corresponds to rotation of $\mathrm{D}_{2} \mathrm{O}$ around the O-Na axis. We trust that obtained transition-state TS23 well approximates the actual transition-state.

The isomerization from 3 to 4 occurs via transitionstate TS34, and it is a result of a torsion around C-C $\alpha$ axis. The next step is a migration of sodium cation from one side of the carboxylic group to the middle, through the transition-state TS45, which is only 0.6 to $1 \mathrm{~kJ} \mathrm{~mol}^{-1}$ higher in energy than intermediates 4 and 5 . Zwitterionic intermediate 6 is then formed by proton transfer from carboxylic to $\alpha$-amino group of reaction intermediate 5. Dissociation of 6 forms ion $\mathrm{AlaNa}^{+}(\mathrm{ZW})$.

Hence, perturbation of the $\mathrm{AlaNa}^{+}$from the CS to the $\mathrm{ZW}$ form seams to be a five step reaction with $\mathrm{D}_{2} \mathrm{O}$ acting as a catalyst. The reaction energy barrier is overcome by initial complexation of reactants $\mathrm{AlaNa}^{+}$ and $\mathrm{D}_{2} \mathrm{O}$, which yields $84.4 \mathrm{~kJ} \mathrm{~mol}^{-1}$. It is important to notice that a single molecule of water is sufficient to change conformation of sodiated amino acid. These findings also support assumptions made by Hoyau et al. $[23,24]$ that binding of an additional ligand $\left(\mathrm{D}_{2} \mathrm{O}\right.$ or $\mathrm{ND}_{3}$ ) to $\mathrm{GlyNa}^{+}$would provide enough energy for $\mathrm{CS}-\mathrm{ZW}$ isomerization.

As already mentioned, the same mechanism can be applied for $\mathrm{CD}_{3} \mathrm{OD}$, (vide supra) and, we believe, also for interaction of sodiated amino acid and $\mathrm{ND}_{3}$. There are no obvious reasons why $\mathrm{ND}_{3}$ in the perturbation reaction will not exhibit the same reactive pattern as $\mathrm{D}_{2} \mathrm{O}$.

The exchange mechanism proposed by Cox et al. [10], which requires carboxylic hydrogen to complete first exchange and perturbation, is additionally supported by lack of $\mathrm{H} / \mathrm{D}$ exchange in sodiated amino acid methyl esters.

However, we believe that sodiated amino acid methyl esters do not exchange with deuterium donor for the same reasons as $\mathrm{AlaNa}^{+}(\mathrm{CS})$, depicted in Figure 3a. Perturbation of sodiated amino acid methyl ester in a zwitterionic-like structure is less probable because the additional methyl group on the carboxylic site (also a very important coordination site) poses steric hindrance and inhibits the ability for conformational change. Also, 


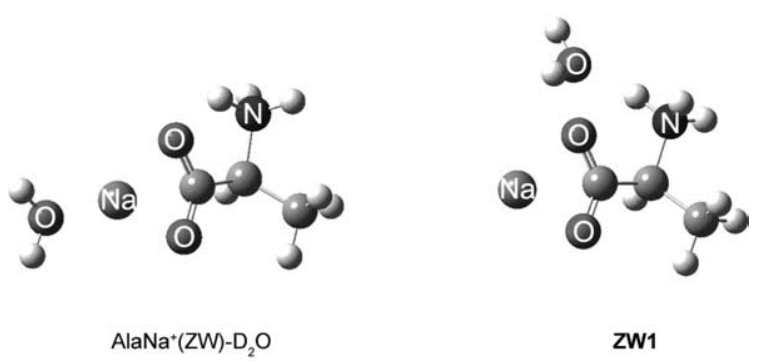

Figure 5. Complexes $\mathrm{AlaNa}^{+}(\mathrm{ZW})-\mathrm{D}_{2} \mathrm{O}$ and $\mathrm{ZW1}$ are results of B3LYP $/ 6-311++\mathrm{G}^{* *}$ optimization of the two stable sites according molecular dynamics simulations.

all our attempts to stabilize the multiply hydrogen bonded reaction complex between the zwitterion-like structure of AlaOMeNa ${ }^{+}$and $\mathrm{D}_{2} \mathrm{O}$ were unsuccessful. During optimization, $\mathrm{D}_{2} \mathrm{O}$ moved either toward sodium cation or away from carbonyl oxygen.

After formation of $\mathrm{AlaNa}^{+}(\mathrm{ZW})$ due to the energetic barrier [20] of $71 \mathrm{~kJ} \mathrm{~mol}^{-1}$, there is a low probability for back isomerization to $\mathrm{AlaNa}^{+}(\mathrm{CS})$, however, reverse $\mathrm{D}_{2} \mathrm{O}$ catalyzed perturbation is possible (vide infra).

\section{$\mathrm{H} / \mathrm{D}$ Exchange of AlaNa ${ }^{+}(\mathrm{ZW})$ with $\mathrm{D}_{2} \mathrm{O}$}

Again, collisions of $\mathrm{AlaNa}^{+}(\mathrm{ZW})$ and $\mathrm{D}_{2} \mathrm{O}$ from various directions were simulated by molecular dynamics calculations. The results show that within 3 ps $\mathrm{D}_{2} \mathrm{O}$ stabilizes at two sites, Figure 5. Optimization of structure $\mathrm{AlaNa}^{+}(\mathrm{ZW})-\mathrm{D}_{2} \mathrm{O}$ gives the energetically most stable complex of $\mathrm{AlaNa}^{+}(\mathrm{ZW})$ and $\mathrm{D}_{2} \mathrm{O}$, with no possibility for $\mathrm{H} / \mathrm{D}$ exchange.
From the aspect of $\mathrm{H} / \mathrm{D}$ exchange, more interesting is a structure where $\mathrm{D}_{2} \mathrm{O}$ is close to the $-\mathrm{NH}_{3}^{+}$group. The interaction brings $\mathrm{D}_{2} \mathrm{O}$ into position which corresponds to starting $\mathrm{H} / \mathrm{D}$ exchange intermediate ZW1, Figure 5. The B3LYP/6-311++ $\mathrm{G}^{* *}$ potential energy profile and optimized structures for the three-step H/D exchange reaction are shown in Figure 6.

The mechanism starts with concerted double transfer of hydrogen/deuterium within ZW1. In the transitionstate TS-ZW12 one of $-\mathrm{NH}_{3}^{+}$group hydrogens is transferred to $\mathrm{D}_{2} \mathrm{O}$ while, simultaneously, one of the deuteriums moves to the carbonyl oxygen. To eliminate dissociation or longer stabilization of reaction intermediate ZW2, molecular dynamics simulations started from this point. Simulations have shown that within 3 ps HDO reaches a position in minimum ZW3 where it partakes in sodium cation solvation. Animated vibration of imaginary frequency of transition-state TSZW23 corresponds to the displacement of HDO towards ZW2 and ZW3. Position of HDO is stable in ZW3 and further dynamics do not suggest any significant movement except oscillation around $\mathrm{C}-\mathrm{C} \alpha$ axis. Finally, in intermediate $\mathbf{Z W 3}$, transfer of the deuteron occurs. Here, the deuteron transfer is identical to the proton transfer in the perturbation reaction of sodiated amino acid from its CS to ZW form. Once minimum ZW4 is formed, the reaction complex dissociates into products $\mathrm{AlaNa}_{\mathrm{D} 1}^{+}$and HDO, where D1 represents the particular hydrogen atom that has been replaced by deuterium.

Although IRC analysis was carried out for reaction pathways, our attempts for IRC analysis of the reaction pathway from transition-state TS-ZW23 to reaction

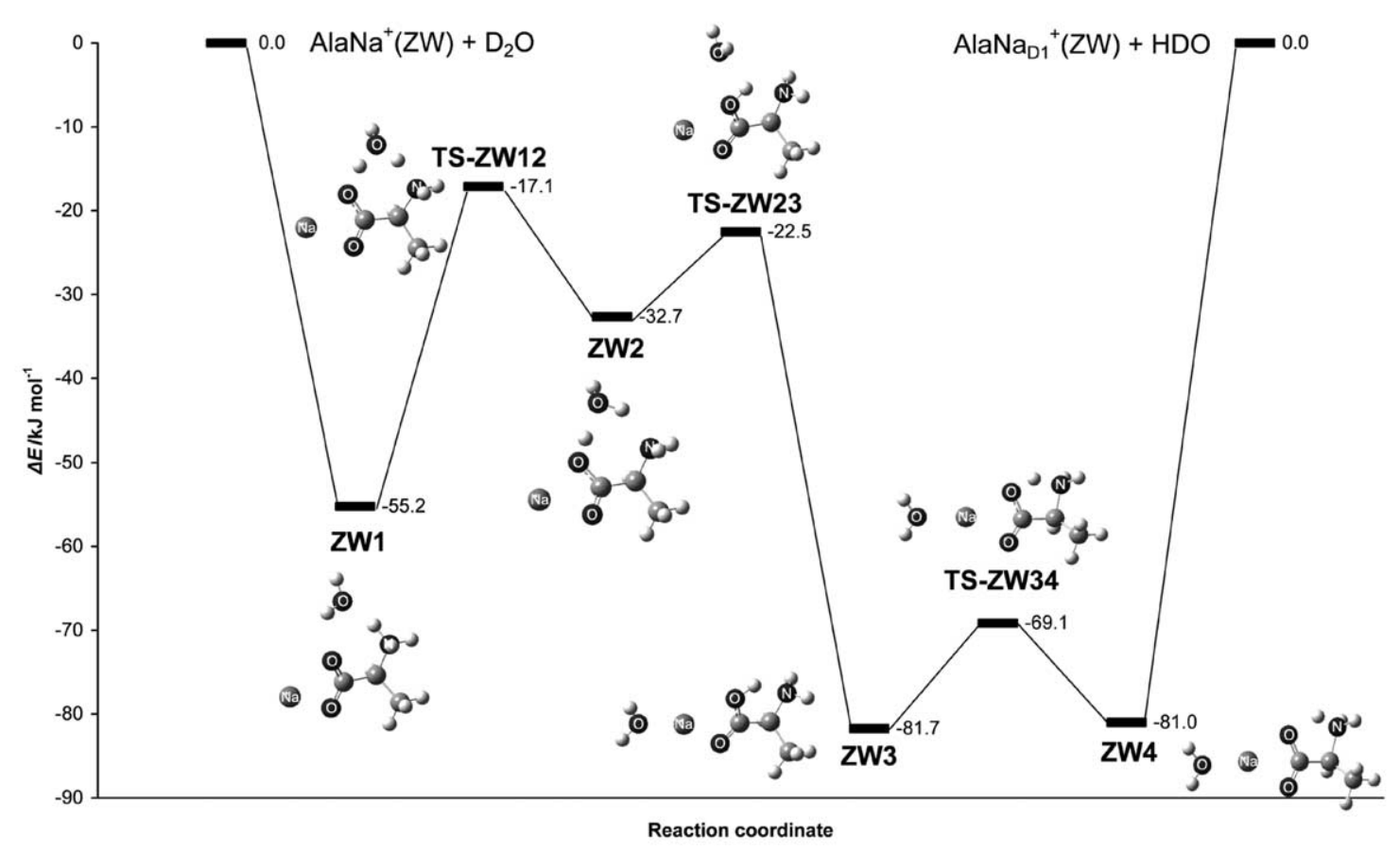

Figure 6. Potential energy profile for the $\mathrm{H} / \mathrm{D}$ exchange reaction of $\mathrm{AlaNa}^{+}(\mathrm{ZW})$ with $\mathrm{D}_{2} \mathrm{O}$. The relative energies and optimized structures were obtained at the B3LYP/6-311++ $\mathrm{G}^{* *}$ level of theory. 


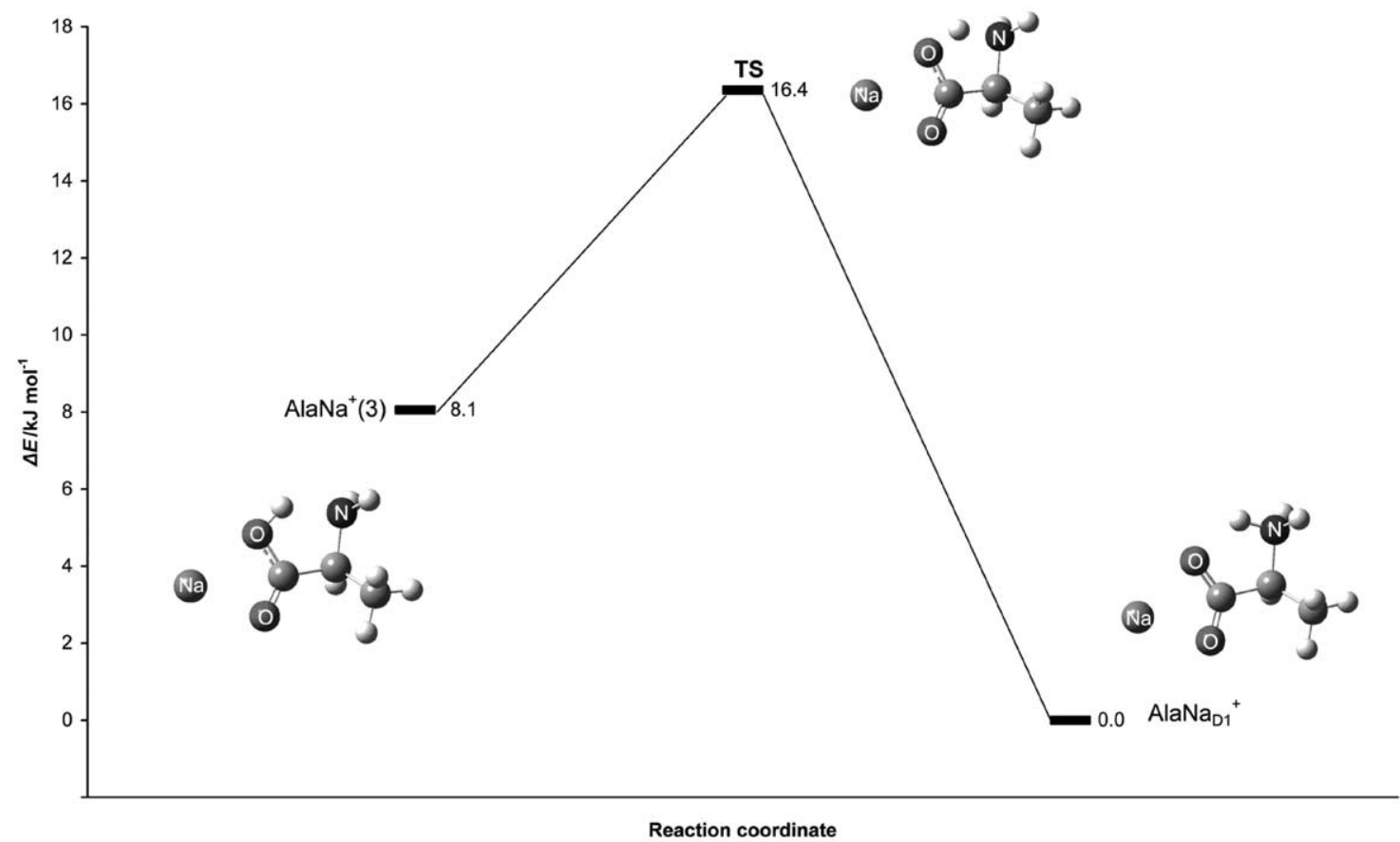

Figure 7. Schematic representation of the potential energy profile for the reaction of the deuteron transfer in $\mathrm{AlaNa}^{+}(3)$. The relative energies are calculated at the B3LYP/6-311++ $\mathrm{G}^{* *}$ level of theory.

intermediate ZW3 were unsuccessful. Because of that and since the energy difference between minima $\mathbf{Z W 3}$ and $\mathbf{Z W 4}$ is very small $\left(0.7 \mathrm{~kJ} \mathrm{~mol}^{-1}\right)$, one should take into account possible dissociation of ZW2 or ZW3. Dissociation of $\mathbf{Z W 2}$ or $\mathbf{Z W} 3$ is a formation of minimum $\mathrm{AlaNa}^{+}(3)$. Minimum AlaNa ${ }^{+}$(3) can either collide with another molecule of $\mathrm{D}_{2} \mathrm{O}$ and form reaction complex ZW3 or rearrange into a minimum $\mathrm{AlaNa}_{\mathrm{D} 1}^{+}$by deuteron transfer from carbonyl oxygen to amino nitrogen, Figure 7. Thus, dissociation of minimum ZW2 or ZW3 results in formation of final product $\mathrm{AlaNa}_{\mathrm{D} 1}^{+}$.

Confirmation of such reaction path is found in the

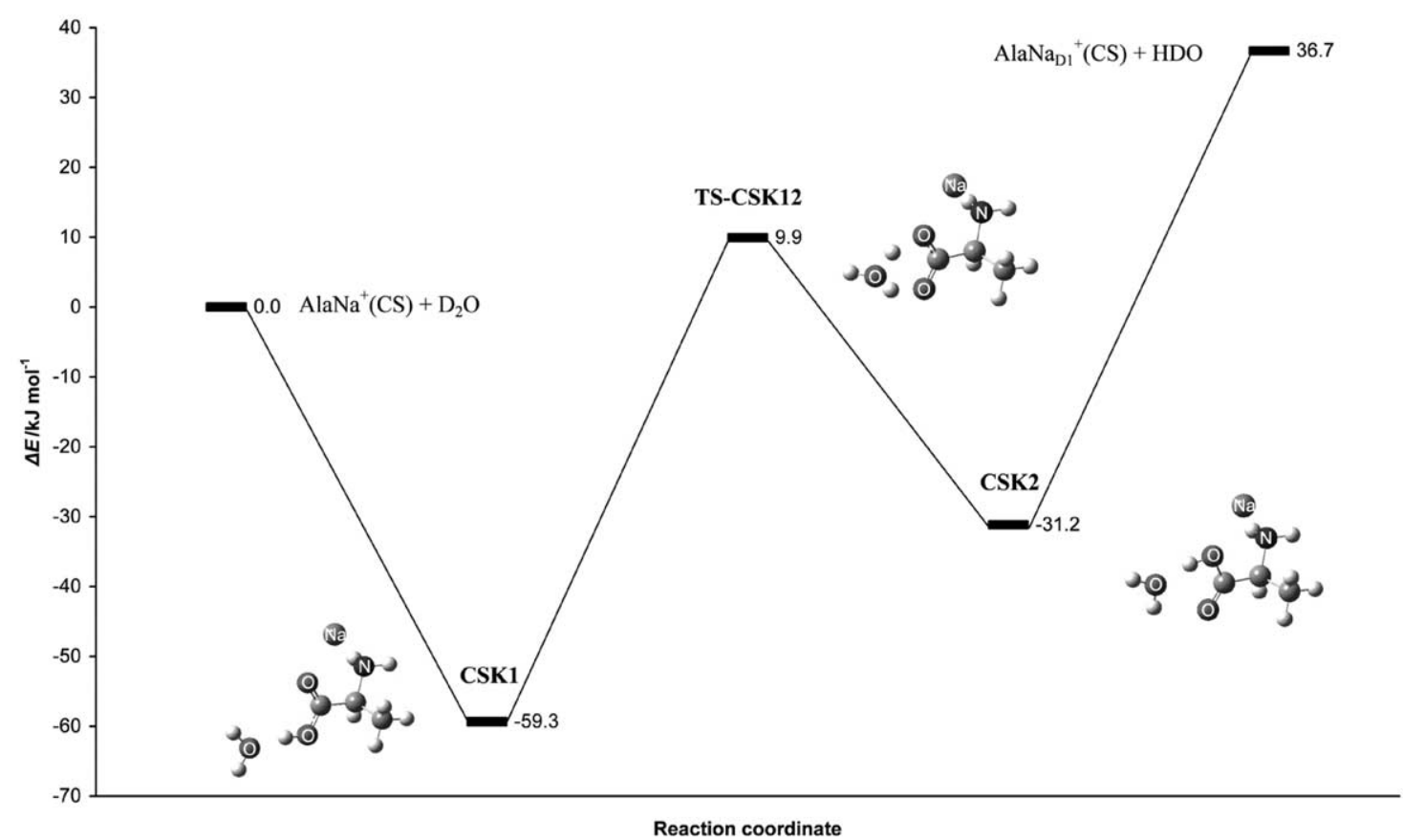

Figure 8. Schematic potential energy diagram for the H/D exchange mechanism of carboxylic hydrogen via "flip-flop" mechanism. The relative energies are calculated at the B3LYP/6-311++G** level of theory. 
experimental values of reaction rates constants. Reaction rate constants for exchange of hydrogens of the $\alpha$-amino group in sodiated amino acids are up to 10 times higher from those in the protonated ones [5-7, 9]. Fast exchanges on $-\mathrm{NH}_{3}^{+}$group suggest absence of rotation of -COOD group around $\mathrm{C}-\mathrm{C} \alpha$ axis and confirm transfer of HDO toward its position in minimum ZW3 [9]. Rotation around $\mathrm{C}-\mathrm{C} \alpha$ axis would slow down the reaction, and observed reaction rates will be lower and more like those for protonated amino acids. Similar behavior, i.e., fast exchanging hydrogens of the amino group can be found in experiments with molecules where the carboxylic group is rigid, e.g., for GlyGlyH ${ }^{+}$[6].

Although subtle, support for this H/D exchange mechanism can be found in the Arrhenius equation. Since it is a mechanism with zero activation energy, the reaction rate constant needs to have a value of the pre-exponential factor. Theoretical values of pre-exponential factors for bimolecular gas-phase reaction with zero activation energy are in the range of $10^{-9}$ to $10^{-11}$ $\mathrm{cm}^{3} \mathrm{~s}^{-1}$ molecule ${ }^{-1}$, i.e., values are pretty much consistent with obtained H/D exchange site-specific reaction rate constants.

With the mechanism of H/D exchange established, the description of interaction between $\mathrm{AlaNa}^{+}$and $\mathrm{D}_{2} \mathrm{O}$ is almost complete. To finish it, the situation that arises from the approach of $\mathrm{D}_{2} \mathrm{O}$ towards the carboxylic group is now considered, Figure $3 \mathrm{~b}$. Examination of this complex addresses the possibility of $\mathrm{H} / \mathrm{D}$ exchange of the carboxylic hydrogen. Experimental results do not indicate the presence of that hydrogen. H/D exchange at the carboxylic oxygen via proton transfer by formation of "hydronium" cation is very unfavorable, and our attempts to find such mechanism were unsuccessful. Although H/D exchange of this hydrogen is possible through a "flip-flop" mechanism (similar to that in protonated amino acids [2,6], Figure 8 , the potential energy profile for such exchange of carboxylic hydrogen shows that energy gained from the formation of the initial reaction complex CSK1 is not sufficient to overcome the barrier of transition-state TS-CSK12. With this in mind, it can be concluded that for interaction between $\mathrm{AlaNa}^{+}(\mathrm{CS})$ and $\mathrm{D}_{2} \mathrm{O}$ the perturbation reaction will be the favored process.

\section{Conclusions}

The major finding of this study and an answer to the question why we see zwitterions is that in a reaction system amino acid-deuterium donor H/D exchange is preceded by a multistep quasi-isoenergetic perturbation, which converts the sodiated amino acid structure from the CS to the $\mathrm{ZW}$ form. The proposed dynamic path for this deuteration reagent catalyzed perturbation is valid for all sodiated amino acids in which the functional side-chain group does not significantly partake in the perturbation. This perturbation mechanism is proposed to apply for $\mathrm{D}_{2} \mathrm{O}$ and
$\mathrm{CD}_{3} \mathrm{OD}$, and there is no reason why not also for $\mathrm{ND}_{3}$ as deuteration reagents.

\section{Acknowledgments}

The authors gratefully acknowledge support by the Ministry of Science, Education, and Sports of the Republic of Croatia.

\section{References}

1. Gard, E.; Willard, D.; Bregar, J.; Green, M. K.; Lebrilla, C. B. Site Specificity in the H-D Exchange Reaction of Gas-Phase Protonated Amino Acids with $\mathrm{CH}_{3} \mathrm{OD}$. Org. Mass Spectrom. 1993, 28, 1632-1639.

2. Campbell, S.; Rodgers, M. T.; Marzluff, E. M.; Beauchamp, J. L. Deuterium Exchange as Probe of Biomolecule Structure. Fundamental Studies of Gas-Phase H/D Exchange Reactions of Protonated Glycine Oligomers with $\mathrm{D}_{2} \mathrm{O}, \mathrm{CD}_{3} \mathrm{OD}, \mathrm{CD}_{3} \mathrm{CO}_{2} \mathrm{D}$, and $\mathrm{ND}_{3}$. J. Am. Chem. Soc. 1995, 117, 12840-12854.

3. Green, M. K.; Lebrilla, C. B. Ion-Molecule Reactions as Probes of Gas-Phase Structures of Peptides and Proteins. Mass Spectrom. Rev. 1997, $16,53-71$.

4. Wyttenbach, T.; Bowers, M. T. Gas Phase Conformations of Biological Molecules: The Hydrogen/Deuterium Exchange Mechanism. J. Am. Soc. Mass Spectrom. 1999, 10, 9-14.

5. He, F.; Marshall, A. G. Weighted Quasi-Newton and Variable-Order, Variable-Step Adams Algorithm for Determining Site-Specific Reaction Rate Constants. J. Phys. Chem. A 2000, 104, 562-567.

6. He, F. Marshall, A. G.; Freitas, M. A. Assignment of Gas-Phase Dipeptide Amide Hydrogen Exchange Rate Constants by Site-Specific Substitution: GlyGly. J. Phys. Chem. B 2001, 105, 2244-2249.

7. Rožman, M.; Kazazic, S.; Klasinc, L.; Srzic, D. Kinetic of Gas-Phase Hydrogen/Deuterium Exchange and Gas-Phase Structure of Protonated Phenylalanine, Proline, Tyrosine, and Tryptophan. Rapid Commun. Mass Spectrom. 2003, 17, 2769-2772.

8. Lifshitz, C. A Review of Gas-Phase H/D Exchange Experiments: The Protonated Arginine Dimer and Bradykinin Nonapeptide Systems. Int. J. Mass Spectrom. 2004, 234, 63-70.

9. Rožman, M. The Gas-Phase H/D Exchange Mechanism of Protonated Amino Acids; J. Am. Soc. Mass Spectrom. 2005, 16, 1846-1852.

10. Cox, H. A.; Julian, R. R.; Lee, S. W.; Beauchamp, J. L. Gas-Phase H/D Exchange of Sodiated Glycine Oligomers with $\mathrm{ND}_{3}$ : Exchange Kinetics Do Not Reflect Parent Ion Structures. J. Am. Chem. Soc. 2004, 126, 6485-6490.

11. Rožman, M. Gas Phase Structure of the Sodiated Amino Acids Probed by H/D Exchange Reactions. Croat. Chem. Acta 2005, 78, 185-188.

12. Curtiss, L. A.; Redfern, P. C.; Raghavachari, K.; Rassolov, V.; Pople, J. A. Gaussian-3 Theaory Using Reduced Møller-Plesset order. J. Chem. Phys. 1999, 110, 4703-4709.

13. Frisch, M. J.; Trucks, G. W.; Schlegel, H. B.; Scuseria, G. E.; Robb, M. A.; Cheeseman, J. R.; Montgomery, J. A., Jr.; Vreven, T.; Kudin, K. N.; Burant, J. C.; Millam, J. M.; Iyengar, S. S.; Tomasi, J.; Barone, V.; Mennucci, B.; Cossi, M.; Scalmani, G.; Rega, N.; Petersson, G. A.; Nakatsuji, H.; Hada, M.; Ehara, M.; Toyota, K.; Fukuda, R.; Hasegawa, J.; Ishida, M.; Nakajima, T.; Honda, Y.; Kitao, O.; Nakai, H.; Klene, M.; Li, X.; Knox, J. E.; Hratchian, H. P.; Cross, J. B.; Adamo, C.; Jaramillo, J.; Gomperts, R.; Stratmann, R. E.; Yazyev, O.; Austin, A. J.; Cammi, R.; Pomelli, C.; Ochterski, J. W.; Ayala, P. Y.; Morokuma, K.; Voth, G. A.; Salvador, P.; Dannenberg, J. J.; Zakrzewski, V. G.; Dapprich, S.; Daniels, A. D.; Strain, M. C.; Farkas, O.; Malick, D. K.; Rabuck, A. D.; Raghavachari, K.; Foresman, J. B.; Ortiz, J. V.; Cui, Q.; Baboul, A. G.; Clifford, S.; Cioslowski, J.; Stefanov, B. B.; Liu, G.; Liashenko, A.; Piskorz, P.; Komaromi, I.; Martin, R. L.; Fox, D. J.; Keith, T.; Al-Laham, M. A.; Peng, C. Y.; Nanayakkara, A.; Challacombe, M.; Gill, P. M. W.; Johnson, B.; Chen, W.; Wong, M. W.; Gonzalez, C.; Pople, J. A. Gaussian 03 Revision B.05; Gaussian, Inc.: Pittsburgh, PA, 2003.

14. Mohamadi, F.; Richards, N. G. J.; Guida, W. C.; Liskamp, R.; Lipton, M.; Caufield, C.; Chang. G.; Hendrickson, T.; Still, W. C. MacroModel-An Integrated Software System for Modeling Organic and Bioorganic Molecules Using Molecular Mechanics. J. Comput. Chem. 1990, 11, $440-467$.

15. Hoyau, S.; Norrman, K.; McMahon, T. B.; Ohanessian, G. A. Quantitative Basis for a Scale of $\mathrm{Na}^{+}$Affinities of Organic and Small Biological Molecules in the Gas Phase. J. Am. Chem. Soc. 1999, 121, 8864-8875.

16. Wyttenbach, T.; Witt, M.; Bowers, M. T. On the Stability of Amino Acid Zwitterions in the Gas Phase: The Influence of Derivatization, Proton Affinity, and Alkali Ion Addition. J. Am. Chem. Soc. 2000, 122, 34583464.

17. Gapeev, A.; Dunbar, R. C. $\mathrm{Na}^{+}$Affinities of Gas-Phase Amino Acids by Ligand Exchange Equilibrium. Int. J. Mass Spectrom. Ion Processes 2003, 228, 825-839.

18. Lemoff, A. S.; Bush, M. F.; Williams, E. R. Binding Energies of Water to Sodiated Valine and Structural Isomers in the Gas Phase: The Effect of Proton Affinity on Zwitterion Stability. J. Am. Chem. Soc. 2003, 125, 13576-13584. 
19. Marino, T.; Russo, N.; Toscano, M. Gas-Phase Metal Ion $\left(\mathrm{Li}^{+}, \mathrm{Na}^{+}, \mathrm{Cu}^{+}\right)$ Affinities of Glycine and Alanine. J. Inorg. Biochem. 2000, 79, 179-185.

20. Marino, T.; Russo, N.; Toscano, M. Potential Energy Surfaces for the Gas-Phase Interaction Between $\alpha$-Alanine and Alkali Metal Ions $\left(\mathrm{Li}^{+}\right.$, $\left.\mathrm{Na}^{+}, \mathrm{K}^{+}\right)$. A Density Functional Study. Inorg. Chem. 2001, 40, 64396443 .

21. Karas, M.; Glückmann, M.; Schäfer, J. Ionization in Matrix-Assisted Laser Desorption/Ionization: Singly Charged Molecular Ions are the Lucky Survivors. J. Mass Spectrom. 2000, 35, 1-12.
22. Kapota, C.; Lemaire J.; Maitre, P.; Ohanessian, G. Vibrational Signature of Charge Solvation vs. Salt Bridge Isomers of Sodiated Amino Acids in the Gas Phase. J. Am. Chem. Soc. 2004, 126, 6485-6490.

23. Hoyau, S.; Ohanessian, G. Interaction of Alkali Metal Cations $\left(\mathrm{Li}^{+}-\mathrm{CS}^{+}\right)$ with Glycine in the Gas Phase: A Theoretical Study. Chem. Eur. J.1998, 4, 1561-1569.

24. Hoyau, S.; Pelicier, J. P.; Rogalewicz, F.; Hoppilliard, Y.; Ohanessian, G. Complexation of Glycine by Atomic Metal Cations in the Gas Phase. Eur. J. Mass Spectrom.2001, 7, 303-311

\section{Appendix}

Absolute energies and relative stabilities of the computed structures.

Table 1. (with Figure 1) The B3LYP/6-311++ $\mathrm{G}^{* *}$ and G3(MP2) energies (in $E_{\mathrm{h}}$ ) and relative stabilities (in $\mathrm{kJ} \mathrm{mol}^{-1}$ ) of the most stable conformers of $\mathrm{AlaNa}^{+}$in a $\mathrm{CS}$ and $\mathrm{ZW}$ form

\begin{tabular}{|c|c|c|c|c|}
\hline \multirow[b]{2}{*}{ Model } & \multirow[b]{2}{*}{ Energy } & \multicolumn{3}{|c|}{$\mathrm{AlaNa}^{+}$} \\
\hline & & CS & ZW & $\Delta_{\text {ZW-CS }}$ \\
\hline $\mathrm{B} 3 \mathrm{LYP} / 6-311++\mathrm{G}(\mathrm{d}, \mathrm{p})$ & $\begin{array}{l}E \\
{ }^{\mathrm{H}} E_{\text {zpe }} \\
{ }^{\mathrm{ANH}} E_{\text {zpe }}\end{array}$ & $\begin{array}{l}-486.011984 \\
-485.901918 \\
-485.903325\end{array}$ & $\begin{array}{l}-486.009987 \\
-485.899784 \\
-485.901507\end{array}$ & $\begin{array}{l}5.2 \\
5.6 \\
4.8\end{array}$ \\
\hline G3(MP2) & $\begin{array}{l}E(0 \mathrm{~K}) \\
E\left(298 \mathrm{~K}, 10^{5} \mathrm{~Pa}\right)\end{array}$ & $\begin{array}{l}-485.018313 \\
-485.009813\end{array}$ & $\begin{array}{l}-485.013976 \\
-485.005256\end{array}$ & $\begin{array}{l}11.4 \\
12.0\end{array}$ \\
\hline
\end{tabular}

Table 2. (with Figure 4) The B3LYP/6-311++ $\mathrm{G}^{* *}$ energies (in $E_{\mathrm{h}}$ ) and relative stabilities of conformers (in $\mathrm{kJ} \mathrm{mol}^{-1}$ ) for the $\mathrm{D}_{2} \mathrm{O}$ catalyzed perturbation of $\mathrm{AlaNa}^{+}$structure from CS to $\mathrm{ZW}$ form

\begin{tabular}{lcc}
\hline Structure & $E$ & \multicolumn{1}{c}{$\Delta$} \\
\hline \hline AlaNa ${ }^{+}(\mathrm{CS})+\mathrm{D}_{2} \mathrm{O}$ & -562.470515 & 0 \\
$\mathbf{1}$ & -562.502679 & -84.4 \\
TS12 & -562.480253 & -25.6 \\
$\mathbf{2}$ & -562.493062 & -59.2 \\
TS23 & -562.482800 & -32.3 \\
$\mathbf{3}$ & -562.483104 & -33.1 \\
TS34 & -562.482739 & -32.1 \\
$\mathbf{4}$ & -562.499811 & -76.9 \\
TS45 & -562.499420 & -75.9 \\
$\mathbf{5}$ & -562.499651 & -76.5 \\
TS56 & -562.494855 & -63.9 \\
6 & -562.499368 & -75.8 \\
AlaNa ${ }^{+}(\mathrm{ZW})+\mathrm{D}_{2} \mathrm{O}$ & -562.468518 & 5.2 \\
\hline
\end{tabular}

Table 3. (with Figure 6) The B3LYP/6-311++ $\mathrm{G}^{* *}$ energies (in $E_{\mathrm{h}}$ ) and relative stabilities of conformers (in $\mathrm{kJ} \mathrm{mol}^{-1}$ ) for the $\mathrm{H} / \mathrm{D}$ exchange reaction of $\mathrm{AlaNa}^{+}(\mathrm{ZW})$ with $\mathrm{D}_{2} \mathrm{O}$

\begin{tabular}{lcr}
\hline Structure & $E$ & \multicolumn{1}{c}{$\Delta$} \\
\hline \hline AlaNa $^{+}(Z W)+$ D2O & -562.468518 & 0.0 \\
ZW1 & -562.489554 & -55.2 \\
TS-ZW12 & -562.475044 & -17.1 \\
ZW2 & -562.480962 & -32.7 \\
TS-ZW23 & -562.477100 & -22.5 \\
ZW3 & -562.499651 & -81.7 \\
TS-ZW34 & -562.494855 & -69.1 \\
5 & -562.499368 & -81.0 \\
AlaNa $_{\text {1 }}{ }^{+}(Z W)+$ HDO & -562.468518 & 0.0 \\
\hline
\end{tabular}

Table 4. (with Figure 7) The B3LYP/6-311++ $\mathrm{G}^{* *}$ energies (in $E_{\mathrm{h}}$ ) and relative stabilities of conformers (in $\mathrm{kJ} \mathrm{mol}^{-1}$ ) for the reaction of the deuteron transfer in $\mathrm{AlaNa}^{+}(3)$

\begin{tabular}{lcr}
\hline Structure & $E$ & \multicolumn{1}{c}{$\Delta$} \\
\hline \hline AlaNa $^{+}(3)$ & -486.006919 & 8.1 \\
TS & -486.003757 & 16.4 \\
AlaNa $_{\mathrm{D} 1}{ }^{+}$ & -486.009987 & 0.0 \\
\hline
\end{tabular}

Table 5. (with Figure 8) The B3LYP/6-311++ $\mathrm{G}^{* *}$ energies (in $E_{\mathrm{h}}$ ) and relative stabilities of conformers (in $\mathrm{kJ} \mathrm{mol}^{-1}$ ) for the $\mathrm{H} / \mathrm{D}$ exchange mechanism of carboxylic hydrogen via "flipflop" mechanism

\begin{tabular}{lcr}
\hline Structure & $E$ & \multicolumn{1}{c}{$\Delta$} \\
\hline \hline AlaNa $^{+}(\mathrm{CS})+\mathrm{D} 2 \mathrm{O}$ & -562.470515 & 0.0 \\
CSK1 & -562.493120 & -59.3 \\
TS-CSK2 & -562.466736 & 9.9 \\
CSK2 & -562.482390 & -31.2 \\
AlaNa $_{\mathrm{D} 1}{ }^{+}$(CS) + HDO & -562.456545 & 36.7
\end{tabular}

